\title{
An Unusual Manifestation of ORF
}

\section{EL Jouari 0*, Gallouj S, Lamouaffeq A, Baybay H and Mernissi FZ \\ Department of dermatology Hassan II University Hospital Fez, Morocco}

*Corresponding author: Ouiame El Jouari, Department of Dermatology and Venereology, University Hospital Hassan II Fez, Morocco, Tel: 00212645768798; Email: eljouariouiame@gmail.com

\section{Case Report}

Volume 3 Issue 1

Received Date: December 20, 2017

Published Date: January 11, 2018

DOI: $10.23880 /$ cdoaj-16000139

\section{Abstract}

The pseudotumoral presentation of Orf is very rare with few cases reported in the literature. It is usually characterized by a single papule which rapidly evolves taking up a nodular appearance. The diagnosis is usually established clinically based on patient history and the characteristics of the nodule. However pseudotumoral forms of this disease requires a skin biopsy in order to eliminate the main its differential diagnoses which are the squamous cell carcinoma and achromic melanoma. Orf is known to generally evolve favorably with a spontaneous regression of lesions. We report the clinical and dermatoscopic aspects of an interesting case involving a giant skin tumor.

Keywords: Tumor of the hand; Parapoxvirus; Dermoscopy

\section{Introduction}

Orf's disease is an infection caused by a cytoplasmic DNA-epitheliotropic virus: Parapoxvirus. It is an endemic zoonosis in the world transmitted by direct contact with infected sheep (sheep, lambs). We report an unusual pseudotumoral clinical form.

\section{Case Presentation}

A 57 year old male patient with a medical history of high blood pressure and diabetes under medication for 20 years and who is also followed for end-stage renal failure consulted at our department for a hemorrhagic erythematous lesion on the right hand that had gradually increased in size. He explained that this new skin lesion had evolved from a skin irritation after he had been exposed to a chemical agent 2 months ago.

The clinical examination revealed a $6 \mathrm{~cm}$, well-defined ulcerous-budding with irregular contours, infiltrated base, surmounted by hemorrhagic crusts in some areas on the thenar eminence of the right hand with other satellite lesions of the same characteristics. The lymph nodes areas of the hand were free of any tumor invasion.

Dermoscopy revealed a papillomatous lesion without specific vascularization. Based on these features the main diagnostics considered were pyogenic granuloma, leishmaniasis, a deep mycosis and achromic melanoma. A skin biopsy was carried out. Histology of the specimen revealed an Orf nodule. We therefore correlated this with te patient's history after further interrogation found that he had raised sheep and goats on a farm and had also handled fresh meat of these animals.

We opted not to perform surgery but to monitor these lesion with local skin care. The alterated general state of patient was related to the patient's hemodialysis. The evolution was marked by the regression the lesions (Figures 1-7). 


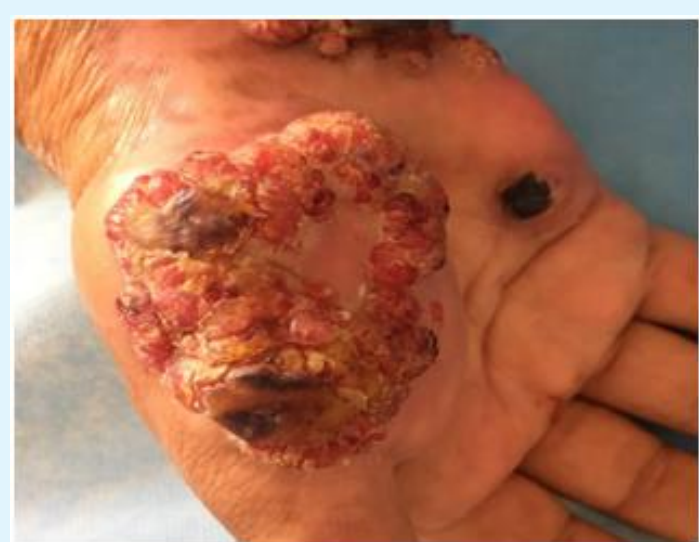

Figure 1: Ulcerous-budding tumor of $6 \mathrm{~cm}$, nippleted, surmounted by hemorrhagic crusts, taking the thear lodge of the right hand with satellite lesions.

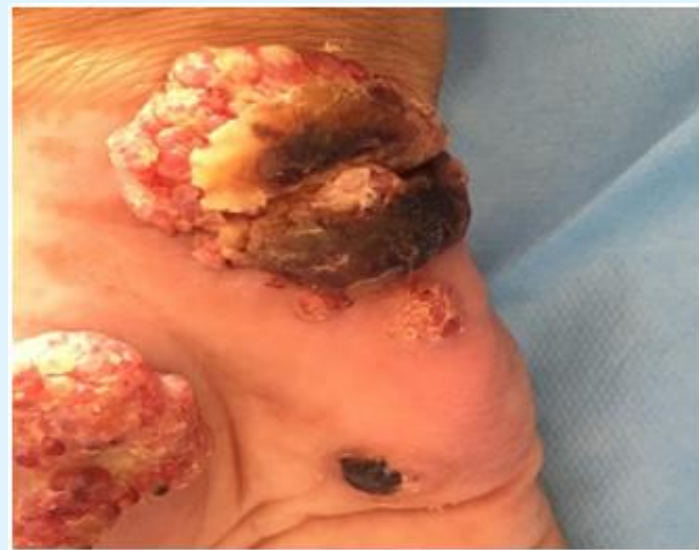

Figure 2 : Ulcerous-budding Tumor of $4 \mathrm{~cm}$, covered with hemorrhagic and mellicheric crusts, localised to the right hand.

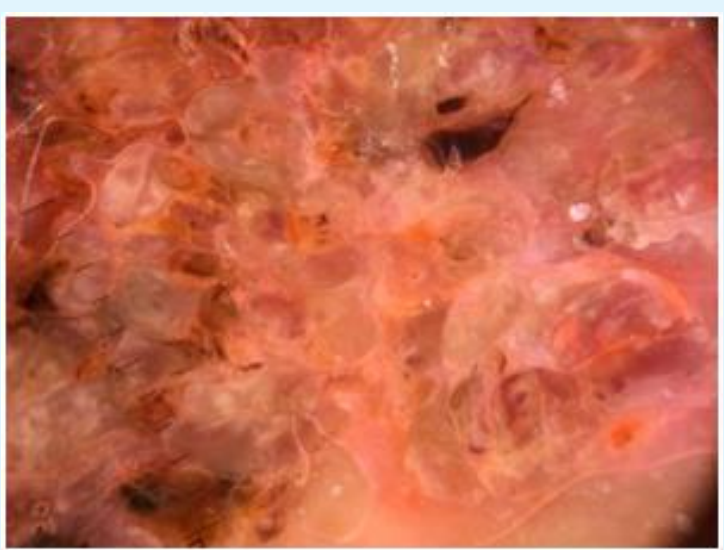

Figure 3: Dermoscopic image: Papillomatous aspect with haemorrhagic and mellicheric crusts.

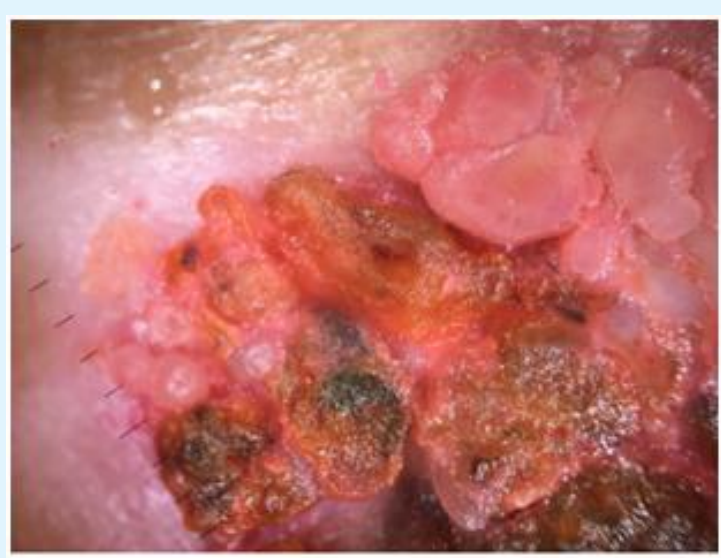

Figure 4: Dermoscopic image after immersion: aspect in rainbow, polymorphic vascularization within the papillae.

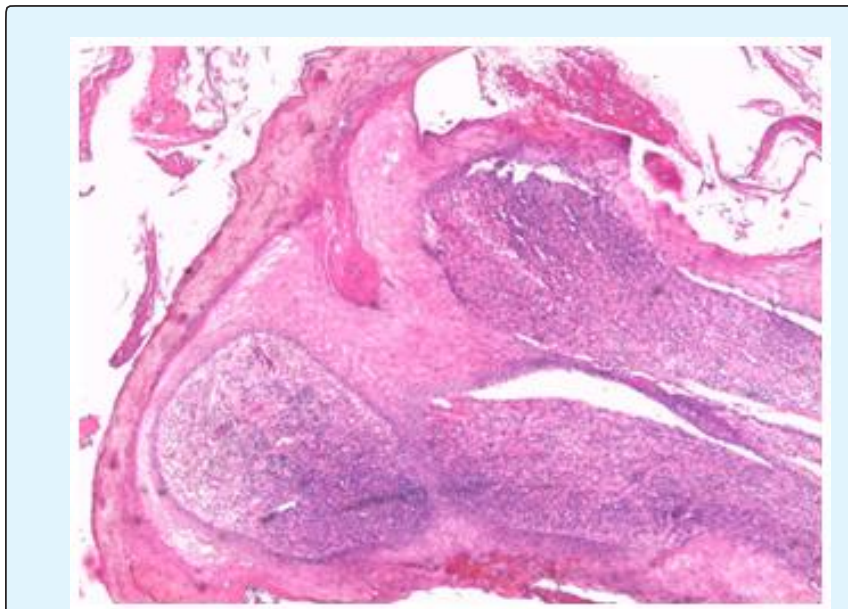

Figure 5: Histological image: Coloration HES G x 50: Hyperacanthosis, papillomatosis, hyperkeratosis and dermal inflammatory infiltrate.

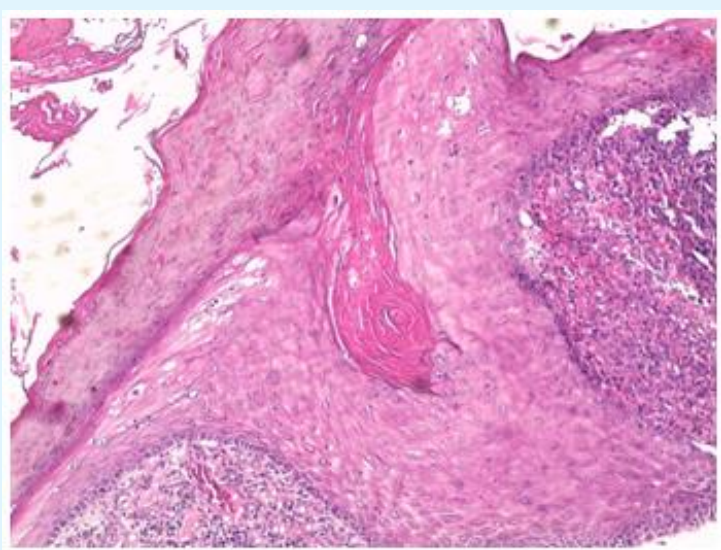

Figure 6: Histological image: Coloration HES G x 100: Vacuolated keratinocytes in surface, sometimes binucleated. 


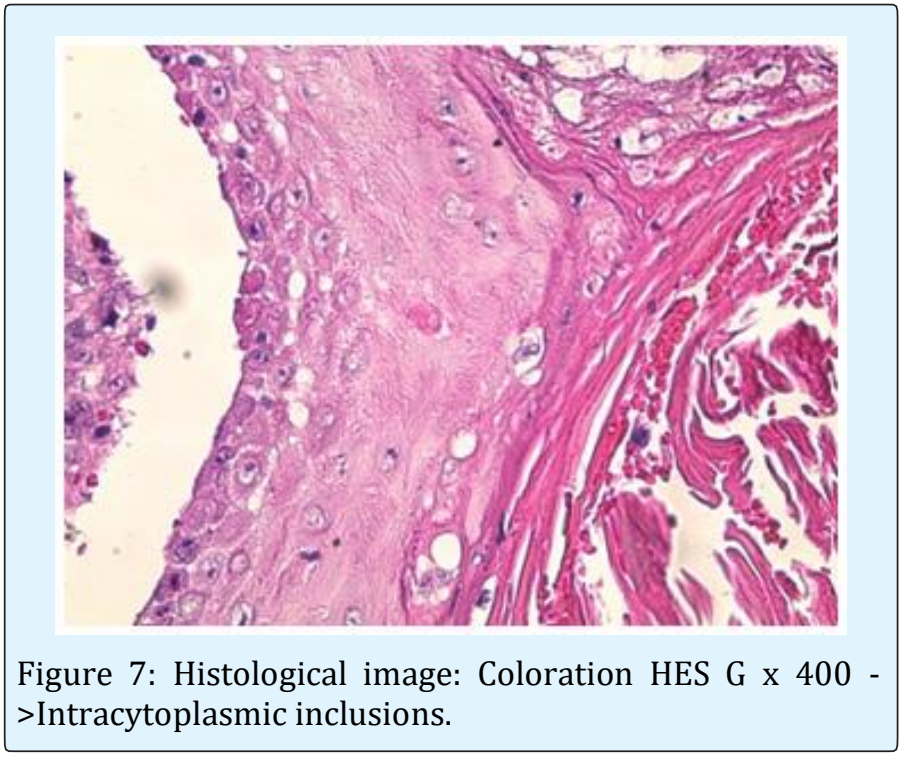

\section{Discussion}

Orf disease or ecthyma contagiosum occurs after an incubation period of 21 days in the form of a single papule and then evolves conventionally in several steps, successively taking on a nodular appearance [1]. Nonsensitive lymphadenopathy may accompany the eruption, as well as mild fever or lymphangitis. Multiple or giant forms of this disease are mostly found in immunosuppressed patients [2]. Frequently affected areas of the body are areas of contact with meat, including the hands, arms, legs and face [1,2].

Differential diagnoses are based on the clinical presentation of the disease. Squamous cell carcinoma and achromic melanoma can be considered in its pseudotumoral form, [3]. The diagnosis is usually established clinically based on the characteristic features of the nodule and patient history. However, biopsy is essential in the pseudotumoral forms [2,3]. Management of this disease usually involves a simple monitoring of this lesion, considering the favorable development and the spontaneous regression in 6 to 12 weeks without any scar. A three times application every week of 5\% imiquimod combined disinfection of the lesion with povidone-iodinehas been tested and found to be effective after two weeks [4]. Non-manipulation of the lesion is essential to avoid extension. Prevention involves good hand hygiene and the use of physical barriers such as gloves [5]. Patients with impairment of the skin barrier (atopic dermatitis, immunocompromised) should avoid contact with potentially infected animals and equipments. Vaccines against this virus are being tested [6].

\section{Conclusion}

The pseudotumoral manifestation of Orf is rarely described. The interest of this case is to consider Orf disease when a sudden and rapid evolving tumor appears on the hand.

\section{References}

1. Chabberta $\mathrm{CH}$, Adamskia I, Moustaghfira S, MinjolleChab, Duvalc HJ, et al. (2009) A painful and exophytic hand lesion. Annales de dermatologie et de vénéréologie 136: 912-914.

2. Malik M, Bharier M, Tahan S, Robinson-Bostom L (2009) Orf acquiredduring religious observance. Arch Dermatol 145(5): 606-608.

3. Nurdogan Ata, Halil Emre Gogus, Selcuk Kilic (2017) Giant Orf on the Nose. J Craniofac Sur 28 (3): e234e235.

4. Ghislain PD, Dinet Y, Delescluse J (2001) Orf en milieu urbain et coutumes religieuses. Ann Dermatol Venereol 128(8-9): 889-892.

5. Bergqvist $\mathrm{CH}$, Kurban M, Abbas O (2017) Orf virus infection. Rev Med Virol 27(4): e1932.

6. Musser JM, Taylor CA, Guo J, Tizard IR, Walker JW (2008) Development of a contagious ecthyma vaccine for goats. Am J Vet Res 69(10): 1366-1370. 